\title{
Новейшие тенденции в области безопасности и устойчивости на Южном Кавказе
}

\author{
Ричард Гирагосян и Сергей Минасян *
}

\section{Введение}

После двадцати лет независимости три страны Южного Кавказа-Армения, Азербайджан и Грузия,--продолжают бороться с пугающим количеством проблем. В свете нескольких неразрешенных конфликтов и почти полного отсутствия усилий, направленных на демократические и экономические реформы, Южный Кавказ остается «регионом риска». И как будто этого пустынного пейзажа недостаточно, появились три новые тенденции, угрожающие стабильности и безопасности региона. Первая и, похоже, имеющая наиболее сильный эффект в долгосрочном плане, видна в медленном сдвиге в уже чувствительном равновесии сил в регионе, подталкиваемая в основном постоянным ростом военных расходов Азербайджана и обостряемая отсутствием прогресса в улаживании конфликта в Нагорном Карабахе. С начала перемирия в 1994 году, в результате которого вооруженные действия в Нагорном Карабахе были приостановлены (но не прекращены окончательно), этот неразрешенный или «замороженный» конфликт стал объектом международного посредничества, проводимого Организацией по Безопасности и Сотрудничеству в Европе (ОБСЕ), так называемой Минской группой. Эта трехсторонняя группа под совместным председательством Франции, России и Соединенных Штатов стремится включить и подтолкнуть стороны конфликта к его разрешению путем переговоров.

За последние два года, однако, напряжение сильно повысилось, число стычек и нападений увеличилось, и нарушения перемирия воссоздали угрозу возобновления войны. В ответ на это, основной фокус дипломатических усилий изменился в сторону возвращения «назад к основам», сдвигаясь от прямого разрешения конфликта к более фундаментальной задаче его предотвращения. Но перспективы для дипломатии остаются весьма мрачными, особенно имея в виду тот факт, что Азербайджан не ищет реального прогресса в мирном процессе, а вместо этого вернулся к политике угроз, предупреждая о военном варианте разрешения конфликта. Это привело к возобновлению опасности, что Нагорно-Карабахский конфликт быстро может перейти от тихо бурлящего, но (управляемого) «замороженного» состояния в категорию «горячих» конфликтов. И хотя признаки возможного возобновления враждебных действий были ясно видны в течении некоторого времени-замечалась эскаляция столкновений по линии разделения Нагорного Карабаха от Азербайджана,—вне региона на эту опасность мало кто обращал внимание.

Ричард Гирагосян является директором Центра Региональных Исследований (ЦРИ), др. Сергей Минасян возглавляет кафедру Политических исследований института Кавказа, два независимых интеллектуальных центра в Ереване. 


\section{Оценка угрозы войны в Карабахе}

В смысле оценки угрозы войны, последнее развитие событий показывает, что опасность возобновления враждебных действий в Нагорном Карабахе сейчас выше, чем когда-либо со времени заключения соглашения о прекращении огня в 1994, которое фактически приостановило вооруженный конфликт. Конкретнее, это увеличение опасности определяется несколькими факторами. Первое, Азербайджан разжег опасную «гонку вооружений» в регионе, постоянно увеличивая свой военный бюджет в течении последних несколько лет, от 175 миллионов долларов США в 2004 до 3.1-3.3 миллиарда в 2011, что составляет 20 процентов от всего госбюджета и включает 1.4 миллиарда, предназначенные для модернизации «путем доставки современного вооружения и оборудования». ${ }^{1}$

Хотя постоянное увеличение оборонных расходов Азербайджана в основном следует интерпретировать в свете его попытки добиться военного превосходства над своими соперниками, оно так же отражает стратегию Азербайджана заставить Армению стремиться к аналогичному увеличению, таким образом оказывать давление на гораздо меньший бюджет Армении и воспользоваться возникающим ощущением армянской слабости и уязвимости. Более того, несмотря на резкое увеличение оборонных расходов, эффект от существенных затрат в течении последних несколько лет был весьма ограниченным в смысле увеличения реального военного потенциала Азербайджана, главным образом из-за окопавшейся в азербайджанских вооруженных силах коррупции. ${ }^{2}$ В последнее время, однако, Азербайджан, выделяет значительную часть своего оборонного бюджета на доставку новых, современных систем, предназначенных для нападения.

Другим важным фактором, обостряющим напряжение, является растущая фрустрация Азербайджана, вследствии отсутствия прогресса в Карабахском мирном процессе. С тех пор как открытые враждебные действия были прекращены в 1994, неразрешенный Нагорно-Карабахский конфликт стал фокусом международных посреднических усилий, направленных на достижение договоренностей, которые будут в состоянии разрешить органическое противоречие между территориальной целостностью и правом на самоопределение. Что делает нынешнюю ситуацию гораздо более серьезной, чем предыдущие циклы увеличенных расходов и риторики, это тот факт, что впервые существует прямая связь между открытыми угрозами и увеличенным потенциалом для нападательных военных действий. Как минимум, текущая ситуация требует новой попытки укрепить и углубить существующее соглашение о прекращении огня путем расширения миссии и мандата наблюдателей ОБСЕ. Имея ввиду недавнюю эскаляцию напряжения и спорадические стычки, необходимо обратить внимание на уязвимость текущего режима перемирия, что

1 “Azerbaijan to Nearly Double Defense Spending,” Agency France-Presse (12 October 2010).

2 Для информации о коррупции в Вооруженных силах Азербайджана, смотри Liz Fuller and Richard Giragosian, “Azerbaijan's Unsinkable General," Radio Free Europe/Radio Liberty (RFE/RL) Caucasus Report (14 March 2010); and Richard Giragosian, "Looking to 2020: Azerbaijan's Military Aspirations," Jane's Islamic Affairs Analyst (23 April 2008). 
должно стать непосредственным приоритетом для международного сообщества. Таким образом, существует очевидная необходимость ослабить напряжение, предотвратить войну и вдохнуть жизнь в заглохнувший мирный процесс. Для этого нужна новая стратегия, гарантирующая, что Карабах не перейдет из состояния замороженного конфликта к серьезной «горячей» войне.

\section{Нагорный Карабах и теория сдерживания}

Ввиду невозможности достичь окончательного компромиссного решения, даже в среднесрочном плане, главной целью в связи с Карабахским конфликтом должно быть сохранение стабильности. Этот контекст на микро-уровне напоминает Холодную войну, во время которой поддержание стабильности служило предотвращению войны между двумя сверхсилами, попавшими в капкан биполярной конфронтации. Эта стабильность была возможна благодаря использованию двух дополняющихся взаимно инструментов политики сдерживания - военного устрашения и политического сдерживания. И тот, и другой в полной мере могут быть применены в Карабахском конфликте. ${ }^{3}$ Более того, поскольку угроза возобновления военных операций сейчас исходит только из Баку, политика сдерживания используется в основном Арменией с целью предотвратить новые столкновения в Карабахе.

В целом, Армения стремится «увеличить цену войны», угрожая целям, связанным с производством энергии и транспортной инфраструктурой в Азербайджане. Чтобы добиться этого, ей нужны оружия, которые в состоянии наносить эффективные упреждающие удары против критических целей вглубь территории вероятного противника. Имея ввиду слабость военно-воздушных сил обеих стран, такими оружиями могут быть тяжелая артиллерия, тактические среднего радиуса и оперативно-тактические дальнего радиуса действия ракеты и крупнокалиберные реактивные системы залпового огня (РСЗО). При оценке локального военного равновесия становится ясно, что несмотря на больший арсенал ракет дальнего радиуса действия, Азербайджан остается уязвимым для атак на его энергетические и промышленные предприятия. Используя свои крупнокалиберные PC3O WM- $80^{4}$ и оперативно-тактические ракеты системы 9K72 типа Эльбрус (SS-1C Scud-B по классификации НАТО), ${ }^{5}$ Армения располагает потенциалом наносить серьезный урон энергетическим, промышленным, инфраструктурным и коммуникационным объектам, находящимся глубоко на территории Азербайджана.

3 Для подробнестей смотри Sergey Minasyan, "The Quest for Stability in the Karabakh Conflict: Conventional Deterrence and Political Containment," PONARS Eurasia Policy Memo No. 188 (September 2011); доступно на http://www.gwu.edu/ ieresgwu/assets/docs/ponars/ pepm_188.pdf.

4 В конце 1990-х Армения получила восемь пусковых установок WM-80 273-мм РСЗО производства Китая (с максимальной дальностью в зависимости от типа от 80 до 120 км).

5 Они были переброшены в Армению из излишков оружия и боеприпасов 176-ой ракетной бригады 7-ой гвардейской армии в процессе распределения советского военного имущества в середине 1990-х. Дальнобойность этих ракет до 300 км, с круговым вероятным отклонением в 0.6 км на больших дистанциях. 
Далее, в середине 2011 появилась информация, что армянская армия располагает новой 300-мм РСЗО Смерч. ${ }^{6}$ Более того, на военном параде в Ереване по случаю двадцатилетия независимости Армении так же были публично продемонстрированы четыре пусковых установки тактических ракет 9К79 «Точка-У». В течении долгого времени то, что у Азербайджана есть такие системы, было для самого Азербайджана аргументом в поддержку возобновления военных действий. ${ }^{7}$ Баку надеялся, что владение такими системами позволит ему проводить «дистанционные» военные операции, что таким образом позволит Азербайджанским вооруженным силам избежать необходимости атаковать укрепленные линии Карабаха, операция, которая сопровождалась бы большими потерями. Но теперь, имея свои системы Смерч и Точка-У, и перспективу приобрести дополнительные ракетные системы дальнего радиуса, Армения существенно укрепила свой потенциал сдерживания. ${ }^{8}$ В результате руководство Азербайджана стоит перед лицом серьезного выбора. Оно могло бы спровоцировать полномасштабную конфронтацию с использованием тяжелой артиллерии с обеих сторон, включая РСЗО и ракеты дальнего радиуса. Однако, это приведет к тяжелым потерям и разрушению большой части энергетической и коммуникационной инфраструктуры без никаких гарантий скорой победы. Так же, такой военный конфликт не может продолжаться долго, так как международное сообщество непременно вмешается.

Альтернативой для Азербайджана является отказ от использования РСЗО и ракет дальнего радиуса в надежде, что Армения тоже воздержится от их использования. Это, однако, маловероятно. Тогда Азербайджан должен будет ограничиться фронтальным нападением «типа Сталинград» с хорошо оборудованной линией укреплений. Тяжелые потери, к которым приведет такое нападение, делают этот вариант неприемлемым. ${ }^{9}$ Очевидно, для Азербайджана трудно выбрать между этими двумя альтернативами. В любом случае, цена войны просто будет слишком высока и результат слишком непредсказуем. Таким образом, похоже, руководство Азербайджана пока остановилось на единственном работающем варианте - гонке вооружений, в надежде истощить Армению и Нагорный Карабах. Однако, даже эта гонка вооружений укрепляет потенциал Армении для сдерживания. Армения в со-

6 Sarkis Harutyunyan, “Armenian Military 'Interested' in Russian Rocket Systems," RFE/RLArmenia (6 June 2011); доступно на www.azatutyun.am/content/article/24228862.html.

7 В 2004-2005 Азербайджан купил у Украины двенадцать пусковых установок для РСЗО 9А52 «Смерч». Дальнобойность РСЗО «Смерч» составляет от 70 до 90 км (в зависимости от типа). В 2008 Баку также приобел как минимум четыре пусковые установки тактических ракет 9К79 «Точка-У».

8 В сентябре 2011 стало известно, что Армения дополнительно приобрела двенадцать 220мм РС3О 9P140 «Ураган»; смотри “Azerbaijan Deplores Reported Armenian Arms Acquisition from Moldova," RFE/RL News (17 October 2011); доступно на www.rferl.org/content/ azerbaijan_armenia_moldova_arms_shipment/24361791.html.

9 Для более детального анализа Карабахского конфликта и вопроса военного баланса см. Sergey Minasyan, "Nagorno-Karabakh after Two Decades of Conflict: Is Prolongation of the Status Quo Inevitable?” Caucasus Institute Research Papers \#2 (Yerevan, August 2010). 
стоянии поддерживать паритет с Азербайджаном, несмотря на высокий уровень военных расходов последнего, благодаря безвозмездным или на преференциальных ценах оружейным поставкам из России, военного и политического союзника Армении. Факт, что Азербайджан покупает вооружение, хотя бы у России, в то время как Армения получает его бесплатно или с большой скидкой, дает возможность Армении держаться вровень с Азербайджаном, поддерживая существующий баланс сил на все повышающемся уровне военного потенциала, таким образом уменьшая вероятность вспышки вооруженных действий. Поддерживание паритета не является гарантией того, что военные действия не будут возобновлены, но это серьезный, эффективный фактор сдерживания.

Другой важный фактор сдерживания проистекает из политического контекста. Политическое сдерживание связано с ролью ключевых политических акторов, которые полностью отвергают разрешение конфликта военными средствами. Источником политического сдерживания является возможность прямого вовлечения России в конфликт в случае возобновления враждебных действий. В настоящее время Армения является единственным государством на Южном Кавказе, у которого есть гарантии безопасности и которое может надеяться получить прямую военную помощь от третьего государства(России), так же как и от более широкого союза, гарантирующего безопасность (Организация Договора Коллективной Безопасности или ОДКБ). Армянская сторона действует с учетом презумпции о гарантии военной помощи со стороны России в случае войны с Азербайджаном. Официально, обязанности России и ОДКБ о взаимной обороне охватывают международно-признанные границы Республики Армения, но не оспариваемые внутренние границы территории Нагорного Карабаха. В случае войны, однако, весьма вероятно, военные действия выйдут за пределы Карабаха и перекинутся на территорию Армении. В таком случае, нежелание обеспечить эффективную и незамедлительную военную поддержку государству-члену может дискредитировать ОДКБ и может привести к непоправимым последствиям. Хотя у Турции и Азербайджана есть договоренность о военной поддержке, подписанное в августе 2010, его формулировки не обвязывающие и в нем нет обязательства прямого военного участия Турции.

\section{Провокация или провидение - напряжение в отношениях России и Грузии}

Другой момент в последнем развитии событий, приведший к малозаметному, но серьезному сдвигу в равновесии региональных сил, является эманацией продолжающегося напряжения между Россией и Грузией. Конкретнее, в результате «Пятидневной войны» между Грузией и Россией в августе 2008, напряжение действительно возросло, так как Россия предприняла шаги к консолидации и расширению своего военного присутствия в Южной Осетии и Абхазии, оказав им поддержку. Россия укрепила свои позиции, расположив две военные базы на территориях Южной Осетии и Абхазии. В состав баз входят объединенные вооруженные формирования (одна бригада и дивизионные подразделения), саперные и артиллерийские подразделения, подразделения сил специального назначения, так же как и форми- 
рования противовоздушной обороны и российских военно-воздушных сил. Россия начала активное строительство и восстановление объектов военной инфраструктуры (вертолетные площадки в Южной Осетии и база в Очамчире для судов береговой охраны в Абазии). Далее, в соответствии с договоренностями с правительствами Южной Осетии и Абхазии, с января 2009 года Россия приняла на себя ответственность за охрану границ, которая была далее расширена соглашением от 30 апреля 2009, позволяющим расположение российских пограничных войск по периметру границ Южной Осетии и Абхазии с Грузией соответственно. ${ }^{10}$ В этом контексте более широкой целью являлось интегрирование вооруженных сил Южной Осетии и Абхазии в качестве доминированного Россией форпоста.

После строительства этих российских военных баз последовало усиление присутствия механизированной пехотной бригады развертыванием дополнительных крупнокалиберных РСЗО «Смерч», а в декабре 2010 также и дивизиона тактических ракет «Точка-У», расположенного в Южной Осетии. Расположение такого «лишнего вооружения» в Южной Осетии, так же как и в Абхазии, далеко выходит за нормальные рамки оперативной боевой готовности к возможному возобновлению военных действий против Грузии, и тут возможны две объяснения. Это может быть признаком подготовки возможного нового русского наступления с целью захвата всей территории Грузии, и даже территорий за ее границами. Или это может служить демонстрацией «превентивного сдерживания» любой эскаляции со стороны Грузии на границе с Южной Осетией и Абхазией, подтверждая желание и готовность России жестко отреагировать на малейший инцидент вдоль границ конфликтной зоны.

Более того, в сентябре 2011, член Президиума Публичного Совета при Министерстве обороны России, хорошо известный журналист Игорь Коротченко, предупредил, что Россия может расположить новые боевые вертолеты Ми-28Н и тактический ракетный комплекс «Искандер-М» в Южной Осетии и Абхазии, если «Грузия продолжит наращивать свой военный потенциал». ${ }^{11}$ Коротченко так же отметил, что передислокация новых ракетных катеров класса «Молния» Черноморского флота России на постоянную стоянку в абхазский порт Очамчира была «разумным

10 Седьмая российская военная база включает бригаду с новой организационной структурой, она одна из первых в Российских Вооруженных Силах, снабженная новыми танками Т-90А (сорок один танк). Ее арсенал состоит из более чем 150 БТР-80А, двух батальонов САУ 2С3 «Акация», батальона РСЗО БМ-21 «Град» и противозенитных комплексов «ОсаАКМ», 3СУ-23-4 «Шилка» и 2С6М «Тунгуска». Четвертая военная база в Южной Осетии в общем имеет батальонную структуру, но ее танковый батальон вооружен танками Т72Б(М). Механизированные пехотные батальоны вооружены БМП-2 вместо традиционных БТР-80А. Для деталей смотри: Антон Лавров, «Послевоенное обустройство Вооруженных сил России в новопризнанных республиках Абхазия и Южная Осетия», в сборнике Танки августа, под ред. Р.Д. Пухова (Москва: Центр анализа стратегий и технологий, 2010).

11 «Россия может разместить ракетные комплексы в Абхазии и Южной Осетии», РИА Новости (22 сентября 2011); доступно на http://ria.ru/defense_safety/20110922/441942516.html. 
шагом». Такое развитие событий ясно показывает, что Москва готова и дальше увеличивать свой военный потенциал в Южной Осетии и Абхазии, считая его не только платформой проецирования силы, но и ресурсом для расширения политического влияния на регион в целом.

В свою очередь, для грузинской стороны, которая больше не в состоянии реагировать на действия России в Абхазии и Южной Осетии, фокус был сосредоточен на создание негативного имиджа России в мировом общественном мнении и на умелую игру на страхах, фобиях и глубоко сидящих антирусских чувствах на Западе. Этот выпад Грузии был направлен как на внутреннюю публику, но также и служил элементом грузинской внешней политики. Внутри Грузии инерция «пятидневной войны» служила основным словесным дискурсом для внешней политики и основой восприятия угрозы. Хотя эффективность паникерской риторики грузинских властей постепенно ослабла, все равно она эффективно обеспечила укрепление позиций правительства Саакашвили в наиболее опасном послевоенном периоде до конца 2010.

Все таки в целом, существует важный фактор, удерживающий Москву от начала новой войны с Грузией, а именно, прямые уроки инвазии в августе 2008 и связанная с ней угроза международной изоляции России. Таким образом, ясно, что несмотря на внешнюю угрозу и враждебную риторику со стороны Москвы, опасность новой войны между Россией и Грузией весьма отдаленна. Уменьшение серьезности этой угрозы подтверждается грузинскими оценками, так же как и направлением военных расходов и оружейных поставок Грузии. Хотя и не в таком количестве как Россия, Тбилиси продолжает поставки оружия и военного оборудования, чтобы возместить потери 2008-го года и переоснастить армию вооружениями нового типа. Это, однако, несравнимо с уровнем оборонных расходов и объемом поставок до войны. ${ }^{12}$ Более того, согласно официальной статистике, в 2008 (учитывая прямые расходы на войну в августе) военный бюджет Грузии составил около 1.625 миллиардов ларов (немного больше, чем 1 миллиард долларов США), тогда как военный бюджет за

12 Согласно Регистру ООН по конвенциональным вооружениям и докладам Стокгольмского международного института исследований проблем мира (СМИИПМ), в 2009 Грузия импортировала двенадцать 152-мм гаубиц Д-20 из Болгарии и двенадцать чешских 122-мм PC 30 RM-70 (опять же из Болгарии). Транспортировка тридцати БТР-70 ДИ и двадцати танков Т-72 из Украины, которая началась до августовской войны, была закончена, так же как и поставка семидесяти бронетранспортеров APC Ejder из Турции. Появились данные о поставке противовоздушных систем из Израиля. Имелась информация о возможной большой поставке новых танков и РСЗО из Украины, хотя неизвестно состоялась она или нет. В 2009 на Украине разгорелся скандал (начатый оппозицией) об экспорте вооружений и военного оборудования в Грузию. Смотри http://unhq-appspub-01.un.org/UNODA/ UN_register.nsf и http://armstrade.sipri.org/armstrade/page/trade_register.php. 
2009 год равнялся 1090 миллионов ларов (665 миллионов долларов США). В 2010 бюджет был урезан до 750 миллионов ларов. ${ }^{13}$

\section{Надежды на армяно-турецкую «нормализацию»}

В отличии от вышеупомянутых тенденций, обсуждаемые в терминах смещающегося баланса в регионе и угрозы возобновления конфликта между разными региональными акторами, существует третья тенденция, с гораздо более положительным характером. Эта тенденция обуславливается возможным рестартом армяно-турецкой нормализации, процесс, позитивное развитие которого дает новую и желанную возможность укрепить стабильность на Южном Кавказе. Хотя в краткосрочном плане перспективы на возобновление дипломатических усилий маловероятны, имея в виду замораживание официальных дипломатических отношений, процесс нормализации отношений между двумя странами продолжается, хотя и ограничивается обменом представителями гражданских организаций и усилиями на «второй дорожке», целью которых является просто «поддержание импульса» до тех пор, пока обе стороны не вернутся к дипломатическим переговорам.

В долгосрочном плане, однако, имеется больше причин для оптимизма. Этот оптимизм проистекает не от участия какой-либо третьей страны, он обуславливается стратегическими расчетами в Анкаре. Точнее, турецкая сторона может действительно рассмотреть возможность вернуться к приостановленному процессу нормализации быстрее, чем ожидается. Конкретнее, в то время как дипломатический процесс между Арменией и Турцией при посредничестве Швейцарии основывался на переоценке Турцией своих национальных интересов, масштаб и спектр вызовов в турецкой внешней политике может инициировать новую переоценку. Необходимость такой переоценки обуславливается обескураживающими и комплексными долгосрочными проблемами, стоящими перед Турцией сегодня, видимыми в нынешнем развитии событий в соседней Сирии, в озабоченности иранской ядерной программой, и в проблемах, вытекающих из конфронтации между Турцией и Израилем. И это только часть примеров. В этом контексте, отсутствие различимого или немедленного успеха в турецкой внешней политике в действительности может привести к политике обращения лицом к Армении, так как нормализация предлагает незамедлительную отдачу, без долгосрочных финансовых и политических инвестиций, которые нужны для преодоления других проблем внешней политики Турции.

И все-таки, возврат к нормализации не будет легким, и у нормализации свои нерешенные проблемы. Отсюда следует необходимость более тонкой политики Турции, основанной на искреннем желании сотрудничать с Арменией, третирующей проблему армянского геноцида более честно и открыто, и признающей факт, что решение Нагорно-Карабахского конфликта не может быть прямым предваритель-

13 По вычислениям и официальным данным за 2008 год, согласно методологии Стокгольмского международного института исследований проблем мира. Смотри так же http://milexdata.sipri.org. 
ным условием для нормализации отношений с Арменией. Но имея в виду то, что от потенциальной армяно-турецкой нормализации выигрывают обе стороны, возможно, Анкара будет в состоянии пополнить копилку внешнеполитических достижений, что ей пока не удается. Как бы там не было, рестарт процесса нормализации потребует от руководства Турции решимости заняться армянским вопросом со всеми проистекающими отсюда последствиями, причем сделать это видимо более искренним способом, чем было до сих пор. Только тогда второй раунд обвязывания может сработать, особенно имея в виду, что международное сообщество смотрит на нормализацию не так, как многие в Анкаре. Действия ожидаются в основном со стороны Турции, так как считается, что Армения более склонна к нормализации отношений.

Понятно, что действительная проблема и действительная тяжесть нормализации теперь лежит на турецкой стороне. Турция закрыла границу с Арменией в 1993 и прервала дипломатические отношения. И что более важно, это Турции надо повернуться лицом к историческому наследству армянского геноцида. Но в то же время, процесс нормализации отношений между Турцией и Арменией создает стратегическую возможность и укрепляет региональную стабильность, решая споры дипломатией, а не силой, в отличии от кровавой грузино-русской войны. Несмотря на скромные успехи прошлых инициатив по нормализации отношений, потенциальные выгоды даже от элементарных форм сотрудничества будут взаимными. Для Турции, - открытие закрытой границы с Арменией создаст новую стратегическую возможность для оживления экономической активности в бедных восточных районах страны, что сыграет ключевую роль в экономической стабилизации уже беспокойных населенных курдами восточных районов и таким образом содействовать основному императиву национальной безопасности Турции - противодействовать источникам курдского терроризма и сепаратизма экономическими средствами. Подобным образом, открытая граница с Турцией даст Армении не только способ преодолеть свою региональную изоляцию и маргинализацию, но и перекинуть мост к большим рынкам, нужным для экономического роста и развития.

В дополнении, коммерческая и экономическая активность, порожденная открытием армяно-турецкой границы, приведет к последующему расширению торговых связей между двумя государствами, что в свою очередь усилит официальное сотрудничество в таких ключевых вопросах, как таможенная и пограничная безопасность. И при таком расширении двухсторонних торговых связей и трансграничного сотрудничества непременно последует установление дипломатических отношений. Таким образом, открытие закрытой армяно-турецкой границы не только приведет к важнейшему прорыву в развитии торговли и экономических связей, но так же даст импульс расширению стабильности и безопасности на территории всего конфликтного Южного Кавказа. 


\section{Литература}

"Azerbaijan Deplores Reported Armenian Arms Acquisition from Moldova." RFE/RL News (2011).

"Azerbaijan to Nearly Double Defense Spending." Agency France-Presse (2010).

Giragosian, Richard. "Looking to 2020: Azerbaijan's Military Aspirations." Jane's Islamic Affairs Analyst (2010).

Harutyunyan, Sarkis. "Armenian Military 'Interested' in Russian Rocket Systems." RFE/RL-Armenia (2011).

Lavrov, Anton. "The Post-war Arrangements of the Russian Armed Forces in the Newly Recognized Republics of Abkhazia and South Ossetia." In The Tanks of August. Moscow: Centre for Analysis of Strategies and Technologies, 2010.

Minasyan, Sergey. "Nagorno-Karabakh after Two Decades of Conflict: Is Prolongation of the Status Quo Inevitable?" Caucasus Institute Research Papers 2 (2010).

Minasyan, Sergey. "The Quest for Stability in the Karabakh Conflict: Conventional Deterrence and Political Containment." PONARS Eurasia Policy Memo No. 188 (2011).

Russia Holds the Capability to Deploy Missile Systems in South Ossetia and Abkhazia In RIA News ., 2011. 